Murooka H, Tsutoma A, Tsuyoshi S, Yusuo I, Mitsukazu N, Nobuhiro $S$. Induction of rest and sleep in the neonates by Nobuhiro S. Induction of rest and sleep in the neonates by

2 Callis PM. The testing and comparison of the intra-uterine sound against other methods for calming babies. Midwives Chronicle 1984;97:336-8.

3 Murray B, Campbell D. Sleep states in the newborn: influence of sound. Neuropadiatrie 1971;2:335-42.
4 Prechtl HFR. The behavioural states of the newborn infant (a review). Brain Res 1974;76:185-212.

5 Birns B, Blank M, Bridger WH. Behavioural inhibition in neonates produced by auditory stimuli. Child Dev 1965;36:639-44.

6 Wood C, Kempson C, Beech C, Brooke OG. An investigation of crying in the newborn in relation to maternal and infan factors. Br $\mathcal{f}$ Obstet Gynaecol 1987;7:201-5.

\title{
Platelet antigens in varicella associated thrombocytopenia
}

Departments of Paediatrics and Clinical Immunology, Karolinska Institute at Huddinge Hospital, Sweden

Correspondence to: Dr J Winiarski, Department of Clinical Immunology Huddinge Hospital, -141 86 Huddinge,

Sweden.

Accepted 29 August 1989

\begin{abstract}
Serum IgG or, predominantly, IgM antibody binding to electrophoretically separated normal platelet membrane protein antigens were detected by immunoblotting in five children with thrombocytopenia associated with varicella. Glycoproteins GPIb, GPIIb, GPIIIa, and other 25-260 kilodalton (kDa) proteins were identified as target antigens, suggesting a transient autoimmune mechanism causing the thrombocytopenia.
\end{abstract}

Purpura is a well known complication of varicella but the mechanisms causing thrombocytopenia have not been fully elucidated. Thrombocytopenia may be caused by either immune mediated platelet destruction ${ }^{1}$ or direct viral interaction with megakaryocytes or platelets. $^{2}$ Circulating platelet binding antibodies and increased platelet associated immunoglobulins have been described, ${ }^{1}$ but the antigenic specificity of the putative platelet binding antibodies has remained unknown. Specific antibodies to defined platelet antigens in thrombocytopenia associated with varicella are reported here.

\section{Patients and methods}

Blood was drawn from three boys and two girls, aged 1.5 to 11 years, within a week after onset of purpura, that presented three to seven days after the eruption of a varicella exanthem. All children were previously untreated and in good health. Nadir platelet counts ranged from $2-7 \times 10^{9} / 1$. A bone marrow examination was performed only in case 3 who, after seven days of purpura, had slightly decreased megakaryocytes. Platelet associated immunoglobulins were increased in three out of three tested patients. The chicken pox was in all cases uncomplicated apart from thrombocytopenia, which resolved (platelet count $>150 \times 10^{9} / 1$ ) within nine to 30 days. Serum samples and normal platelet counts were obtained from four of the children one to seven years later. Sera from 24 healthy blood donors were used as negative controls and anti$\mathrm{Pl}^{\mathrm{Al}}$ sera as positive controls. Separation of platelet membrane glycoproteins using sodium dodecylsulphate-polyacrylamide gel electrophoresis (SDS-PAGE) and immunoblotting were performed as described elsewhere. ${ }^{3}$ Briefly, pooled normal platelet membranes were dissolved in SDS and applied to a slab gel together with molecular weight standards. SDS-PAGE was performed under non-reducing conditions using the discontinuous buffer system of Laemmli. The separated proteins were electrophoretically transferred from gels to nitrocellulose membranes and blocked in fat free milk. Membrane strips were incubated with patient or control sera, diluted 1:25. After several washes the blots were first incubated with alkaline phosphatase conjugated protein A or rabbit antihuman IgM and then stained after addition of substrate for the detection of glycoprotein bound antibodies. Glycoproteins were identified on parallel blots by alkaline phosphatase conjugated Lens culinaris lectin which binds to platelet glycoproteins Ib, IIb, and IIIa. To confirm the specificity for platelet surface antigens, sera were absorbed with fresh platelets ${ }^{3}$ and used in parallel with unabsorbed sera. Sera were also screened with a solid phase platelet membrane enzyme linked immunoadsorbent assay (ELISA). ${ }^{4}$ All positive results were confirmed on repeat testing.

\section{Results}

By immunoblotting, platelet glycoprotein binding IgG was detected in sera from three patients and IgM in five patients. IgM corresponded in part to the IgG bands, but additional reactions were noted. The bands comigrated with GPIb (170 kDa), GPIIb (140 kDa), and GPIIIa $(95 \mathrm{kDa})$ in four patients. Other unidentified 25-260 $\mathrm{kDa}$ bands were also seen (figure and table). Absorptions of sera with packed platelets eliminated antibody binding to glycoproteins Ib, IIb, IIIa and to the other proteins indicating specificity for native surface antigens. By ELISA, four children were shown to have membrane binding antibodies. In sera collected one to seven years later, the earlier positive reactions were mostly weak or no longer detected (table). In case 4 , IgG platelet 
ELISA and immunoblot assays for serum antibodies to platelet antigens in five children with varicella associated purpura and in controls

\begin{tabular}{|c|c|c|c|c|c|}
\hline \multirow[t]{2}{*}{$\begin{array}{l}\text { Case } \\
\text { No }\end{array}$} & \multirow[t]{2}{*}{$\begin{array}{l}\text { Serum } \\
\text { sample } \\
\text { taken* }\end{array}$} & \multicolumn{2}{|c|}{$\begin{array}{l}\text { Presence }(+) \text { or absence }(-) \\
\text { of platelet membrane binding } \\
\text { antibodies in serumt }\end{array}$} & \multicolumn{2}{|c|}{$\begin{array}{l}\text { Antibodies to SDS-PAGE separated } \\
\text { platelet membrane proteinsf }\end{array}$} \\
\hline & & $I g G$ & $I g M$ & $\overline{I g G}$ & $I g M$ \\
\hline 1 & $\begin{array}{l}\text { During } \\
\text { After (1) }\end{array}$ & - & \pm & $\begin{array}{l}38 \\
-\end{array}$ & $\begin{array}{l}25,38,52 \\
(25),(38)\end{array}$ \\
\hline 2 & $\begin{array}{l}\text { During } \\
\text { After (1) }\end{array}$ & ND & + & & \\
\hline 3 & $\begin{array}{l}\text { During } \\
\text { After (4) }\end{array}$ & $\overline{-}$ & - & 25,38 & $\begin{array}{l}25,38,52,170,260 \\
(52),(260)\end{array}$ \\
\hline 4 & $\begin{array}{l}\text { During } \\
\text { After }\end{array}$ & $\stackrel{+}{N D}$ & $\stackrel{+}{N D}$ & $\overline{\mathrm{ND}}$ & ND, \\
\hline 5 & $\begin{array}{l}\text { During } \\
\text { After (7) }\end{array}$ & + & \pm & $\begin{array}{l}95,140 \\
-\end{array}$ & $38,52,95$ \\
\hline \multicolumn{2}{|c|}{ Controls $(n=24)$} & - & - & - & - \\
\hline
\end{tabular}

*Sera were collected during thrombocytopenia and in the convalescent period (No of years after thrombocytopenia). tELISA.

Bands detected by immunoblotting; molecular weights of target antigens in $\mathrm{kDa}$. Parentheses denote a weak reaction. $\mathrm{ND}=$ not done.

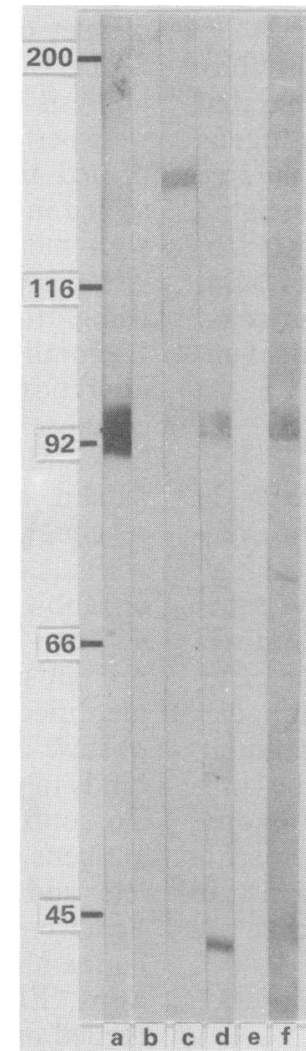

IgG and IgM antibodies to SDS-PAGE separated platelet membrane glycoprotein antigens as detected by immunoblotting in patient and control sera. Apparent molecular weights are given in $k D a$. Lanes $a, b$, and $c$ show platelet antibodies of IgG class and lanes $d, e$, and $f$ of the IgM class. Lane a was incubated with $P l^{A 1}$ antiserum. The IgM class. Lane a was incubated with $P l^{A I}$ alloantigen is situated on GPIIIa $(95 \mathrm{kDa})$. Lanes $b$ and $e$, normal sera; $c$ and d, case 5 . The $140 \mathrm{kDa}$ band in lane c comigrated with GPIIb. Lane $f$, case 2.

membrane antibody was detected in the ELISA but not by immunoblotting. IgG-F $\left(\mathrm{ab}^{\prime}\right)_{2}$ binding to GPIIb/IIIa could be confirmed as previously described. ${ }^{4}$

\section{Discussion}

Various mechanisms underlying the virus associated thrombocytopenias have been proposed. Non-immunological factors such as viral interaction with platelets or megakaryo- cytes have been suggested when purpura presents in the viraemic phase of varicella, ${ }^{4}$ while the 'postinfectious' purpura would more likely be immune mediated. Increased megakaryocyte counts may, however, be found in patients with thrombocytopenia presenting early during the exanthematous phase. Feusner et al reported shortened platelet survival, increased megakaryocyte counts, and platelet binding antibodies in serum and on platelets in four children with varicella associated thrombocytopenia, indicating an immune mediated platelet destruction. ${ }^{1}$

IgG antibodies directed to platelet membrane glycoprotein antigens have been shown in chronic idiopathic thrombocytopenic purpura, confirming the autoimmune nature of that disease. ${ }^{5}$ Few data have been available about the pathogenesis of acute idiopathic thrombocytopenic purpura. Recently antibodies to platelet membrane glycoproteins have been observed, ${ }^{3}$ and also binding via the IgG $F\left(a b^{\prime}\right)_{2}$ part to the GPIIb/GPIIIa complex in patients with acute idiopathic thrombocytopenic purpura. ${ }^{4}$ The present finding of IgG and predominantly IgM antibodies directed to platelet surface glycoproteins, including GPIb, GPIIb, and GPIIIa, during active disease suggests that they may have a role as a thrombocytopenic factor in these varicella patients. The presence of HLA or alloantibodies is unlikely in the untransfused children. In ELISA, with a different antigen presentation, platelet membrane antibodies were detected in four patients. The course of thrombocytopenia might be connected with the primary IgM antibody response to an infection. Varicella zoster virus appears in the blood five days before the onset of a rash. Elicited antiviral IgG is detectable in serum three days after exanthem, by which time the viraemic phase is concluded. ${ }^{6}$ An early thrombocytopenia could be mediated by IgM class platelet cross reactive antibodies or antibodies produced by unspecifically stimulated autoreactive B lymphocytes. It is concluded that the detection of platelet antigen reactive autoantibodies strengthens the concept of a transient autoimmune platelet destruction in children with chicken pox induced thrombocytopenia. 
This work was supported by the Swedish Medical Research Council, the Medical Research Council of the Swedish Life Insurance Companies, the Swedish Society of Medicine, and the Karolinska Institute Foundations.

1 Feusner JH, Slichter SJ, Harker LA. Mechanisms of thrombocytopenia in varicella. Am $\mathcal{F}$ Hematol 1979;7 255-64.

2 Espinoza G, Kuhn C, Viral infection of megakaryocytes in varicella with purpura. Am $\mathcal{F}$ Clin Pathol 1974;61:203-8.
3 Winiarski J. IgG and IgM antibodies to platelet membrane glycoprotein antigens in acute childhood idiopathic thrombocytopenic purpura. Br $\mathcal{F}$ Haematol 1989;73:88-92.

Winiarski J, Ekelund E. Antibody binding to platele antigens in acute and chronic ITP: a platelet membrane ELISA for the detection of anti-platelet antibodies in serum. Clin Exp Immunol 1986;63:459-65.

5 Woods VL, McMillan R. Platelet autoantigens in chronic ITP. Br f Haematol 1984;57:1-4.

6 Asano Y, Itakura N, Hiroishi Y, et al. Viral replication and immunologic responses in children naturally infected with varicelıa-zoster virus and in varicella vaccine recipients. F Infect Dis 1985;152:863-8.

\title{
Is a specialist paediatric diabetic clinic better?
}

\author{
S Bloomfield, J W Farquhar
}

\begin{abstract}
Diabetic control in $\mathbf{8 8}$ children attending three general paediatric clinics was compared prospectively over one year with that of 89 children attending a specialist paediatric diabetic clinic. Glycated haemoglobin $\left(\mathbf{H b A}_{\mathbf{1}}\right)$ concentration and days admitted were significantly lower in the group attending the specialist clinic. This has implications for the organisation of paediatric diabetic services.
\end{abstract}

Diabetic control in many children is not as good as it could be. ${ }^{1}$ It has been suggested that better diabetic control is achieved in children attending specialist paediatric diabetic clinics, ${ }^{2}$ but few objective studies have been done. We have collected, over a one year period, data about diabetic control in children attending a specialist paediatric diabetic clinic in a children's hospital compared with those attending paediatric clinics in three district general hospitals.

\section{Methods}

The diabetic clinic at the Royal Hospital for Sick Children (RHSC) acts as a primary referral centre for children under 16 years in south east Scotland. It is staffed by three paediatricians (two consultants and one senior registrar), one adult diabetologist who facilitates gradual transfer of adolescents to the adult clinics, a dietitian, a full time nurse specialist, and a dental hygienist. There is 24 hour access by telephone to medical or nursing staff for advice and the specialist nurse visits at home as required.

Three general paediatric clinics (A, B, and C) in district general hospitals in central Scotland provide care for diabetic children who are seen by a consultant paediatrician or paediatric registrar. A dietitian is available in all these clinics, and a diabetes nurse specialist who is shared part time with the local adult clinics is sometimes available.

Information about children under 13 years of age on 1 October 1985, and with diabetes of more than three months duration, was obtained prospectively for one year as part of a research project concerning diabetes education. Data included a medical and social profile, methods of diabetic care, diabetic events, anthropometric measurements, and measurement of glycated haemoglobin $\left(\mathrm{HbA}_{1}\right)$ at each visit. (All blood samples for $\mathrm{HbA}_{1}$ were analysed at RHSC by a Corning electrophoretic method; the normal reference range is $4 \cdot 7-7 \cdot 9 \%$. Samples were analysed within one week and remained stable. ${ }^{3}$ )

Data from the three district general hospitals and the RHSC clinic were compared by $\chi^{2}$ or Kruskal-Wallis tests as appropriate, and associations between quantitative and ordinal variables were tested by Kendall rank correlation.

\section{Results}

Comparisons were made at the end of one year (a) between the three general paediatric clinic populations, and (b) for all these three clinics combined (if there was no significant difference between them) with the RHSC paediatric diabetic clinic. Age, duration of disease, age at diagnosis, the number of boys, and social class distribution were similar (table 1). The average time spent with the paediatrician at each clinic visit was 25 minutes at RHSC and approximately 15 minutes in the general clinics.

Children attending the clinic at RHSC were admitted to hospital for significantly fewer days
Department of

Child Life and Health,

University of Edinburgh

$S$ Bloomfield

J W Farquhar

Correspondence to:

Dr S Bloomfield

Child Life and Health,

17 Hatton Place,

17 Hatton Place,
Edinburgh EH9 $1 \mathrm{UW}$.

Accepted 7 September 1989
Table 1 Characteristics of diabetic children $<13$ years of age attending paediatric clinics in district general hospitals $(A, B, C)$ and a specialist paediatric diabetic clinic (RHSC)

\begin{tabular}{|c|c|c|c|c|}
\hline & $\begin{array}{l}A \\
(n=40)\end{array}$ & $\begin{array}{l}B \\
(n=24)\end{array}$ & $\begin{array}{l}C \\
(n=24)\end{array}$ & $\begin{array}{l}\text { RHSC } \\
(n=89)\end{array}$ \\
\hline $\begin{array}{l}\text { Mean (SD) age (years) } \\
\text { Mean (SD) duration diabetes (years) } \\
\text { Male/female } \\
\text { No in social class I and II }\end{array}$ & $\begin{array}{l}10 \cdot 7(2 \cdot 6) \\
4 \cdot 2(2 \cdot 5) \\
16 / 24 \\
13\end{array}$ & $\begin{array}{c}11 \cdot 1(1 \cdot 9) \\
4 \cdot 9(2 \cdot 8) \\
10 / 14 \\
6\end{array}$ & $\begin{array}{l}10 \cdot 2(2 \cdot 4) \\
3 \cdot 3(1 \cdot 7) \\
7 / 17 \\
12\end{array}$ & $\begin{array}{l}10 \cdot 6(2 \cdot 8) \\
4 \cdot 6(2 \cdot 8) \\
39 / 50 \\
32\end{array}$ \\
\hline
\end{tabular}

There was no significant difference between groups for any variable. 